RESEARCH ETHICS

\title{
Stroke patients' preferences and values about emergency research
}

\author{
C E Blixen, G J Agich
}

J Med Ethics 2005;31:608-611. doi: 10.1136/jme.2004.010488

See end of article for authors' affiliations ......................

Correspondence to: Carol E Blixen, Department of Biostatistics and Epidemiology WB-4, The Cleveland Clinic Foundation, 9500 Euclid Avenue, Cleveland, $\mathrm{OH}$ 44195, USA;

blixenc@ccf.org

Received 2September 2004 In revised form 29 December 2004 Accepted for publication 11 January 2005
Background: In the USA, the Food and Drug Administration waiver of informed consent permits certain emergency research only if community consultation occurs. However, uncertainty exists regarding how to define the community(ies) or their representatives.

Objective: To collect data on the actual preferences and values of a group-those at risk for stroke-most directly affected by the waiver of informed consent for emergency research.

Design: Face to face focused interviews were conducted with 12 patients who were hospitalised with a stroke diagnosis in the previous year. The interviews were audiotaped and a transcript based method was used for their analysis.

Results: All 12 participants felt "that it was important that new treatments for stroke be developed", but they were initially confused about the distinction between "research for stroke" and "emergency research for stroke". However, after explanation, most ( $n=10 ; 83 \%)$ expressed willingness to participate in the latter. In the absence of a surrogate to give informed consent in a stroke emergency situation, the majority ( $n=11 ; 92 \%$ ) said they would want the physician to "go ahead and enrol them in the trial".

Conclusions: This study is the first to identify the values and concerns of individuals most directly affected by stroke emergency research. Further interviews and focus groups are needed to develop and test a validated questionnaire on the preferences and values surrounding emergency research for stroke.
C onducting research ethically in emergency settings poses well recognised challenges, including that of informed consent. To address these concerns, an exemption from the requirements for informed consent was adopted by the United States Department of Health and Human Services and the Food and Drug Administration in 1996. ${ }^{1}$ The waiver of informed consent requirements can be granted only if additional procedures are followed, including consultation with the community in which the research will occur. However, there is little consensus in the literature regarding the appropriate methods of consultation, the objectives of such consultation, or the specific relevance of consultation to the requirement for informed consent that is waived. ${ }^{2}$ There is also uncertainty regarding who constitutes the community(ies) or how the true representatives of the community(ies) should be identified. A Food and Drug Administration Draft Guidance document distinguishes the communities from which and in which the study is conducted, but does not specify further the consultative processes that should be applied. ${ }^{3}$ Considerable confusion about the requirement and its bearing on the protection of research participants impedes the development of protocols. ${ }^{45}$ Thus, a reliable and workable approach to identifying the values of the relevant community is a basic ethical prerequisite for the waiver of consent for emergency research in not only stroke but other diseases as well.

Because stroke patients are triaged to emergency departments without regard for their cultural, ethnic, racial, or self-identified community identities, identifying the relevant community for consultation purposes is a significant problem. The objective of this pilot study, therefore, was to identify the actual preferences and values of a group most directly affected (those who have experienced a stroke and are at risk for another) in order to allow their incorporation into the design of further research studies for stroke.

\section{MATERIALS AND METHODS \\ Study design}

We selected qualitative methods (focused interviews) for this cross-sectional study because of a lack of data on stroke patients' preferences and values about emergency research, and the need to provide a foundation for continued enquiry. Qualitative studies offer a valuable approach when research questions are not well established or when conventional theories and approaches are inadequate. ${ }^{6}$

\section{Sample selection and recruitment}

Approval for this study was obtained from the Institutional Review Board of the Cleveland Clinic Foundation. Stroke patients have a 6-9\% annual risk of recurrent stroke and a $3.2-3.5 \%$ annual risk of vascular death, ${ }^{7}$ so we identified the "relevant community" for our study as those people who had suffered a stroke in the previous year. Potential participants were selected from a list generated by the Cleveland Clinic's Stroke Program. Persons 18 years of age and older who were discharged home in 2002 with a primary diagnosis of stroke (ICD-9 codes 433, 434, 436 for infarct; ICD-9 code 431 for intracerebral haemorrhage) were included. Purposive sampling was used to reflect the racial, gender, and age distribution of stroke nationally. ${ }^{7}$ A letter from a physician in the Department of Neurology describing the project was then sent to prospective participants who were African American and Caucasian men and women in the age groups $35-54,55-64$, and 65 years and over. They were asked to contact the principal investigator (CB) by telephone if they were interested in participating. During the telephone conversation, the principal investigator again explained the project and assessed whether the prospective participant had any problems with comprehension and speaking. Those who were without cognitive deficit were invited to schedule a

Abbreviation: ERS, emergency research for stroke 
1-hour interview. Recruitment continued until people who met the age, gender, and race requirements were interviewed and theoretical saturation was reached $(n=12)$. With theoretical saturation, sampling continues until no new data emerge. $^{8}$

The sample consisted of an equal number of African American and Caucasian male and female participants $(n=$ 12 ) with a mean age of 55.2 years ( $S D=7.63)$. Half $(50 \%)$ of the sample were married and employed, and half $(50 \%)$ had had one or more previous strokes, but the number of strokes was higher in the African Americans $(n=7)$ than in the Caucasians $(n=3)$. This was consistent with the American Heart Association's findings that African Americans between the ages of 35 and 54 years have a risk of stroke four times that of white Americans. ${ }^{7}$

\section{Data collection}

After the patients demonstrated an understanding of the interview process and written informed consent was obtained, face to face focused interviews were conducted and audiotaped. The goal of these interviews was to explore openly the values and preferences of potential participants in emergency research for stroke (ERS). An interview guide was used to help to focus the interview. This listed the main topics to be covered in the interview and the specific topic related questions to be asked. For example, under the topic "knowledge about emergency research for stroke", the following questions were asked: "Can you tell me what you know about emergency research for stroke?" followed by, "What information would be important for you to know if you had to make the decision to agree to an emergency intervention for stroke?" and, "Can you tell me about the level of confidence you have in the ability of your spouse/significant other to make a judgement for you if you could not give consent for an emergency intervention for stroke?" The guide also included some ideas about follow-up questions or probes such as "would you explain further", "please describe what you mean" and, "would you give me an example". The main topics that informed the questions used in the study were:

- Understanding of research related terms;

- Attitude towards current health care providers and their engagment in research;

- Attitude towards new treatment for stroke;

- Attitude about importance of informed consent and surrogate consent;

- Attitude about being included in a trial without giving informed consent;

- Knowledge about ERS;

- Attitude towards participation in ERS;

- What informed consent for ERS should include;

- Adequacy of surrogate consent by a family member in ERS;

- Personal tolerance for risk in ERS;

- What doctors should do if there is not time to obtain informed consent in ERS.

\section{Data analysis}

The audiotapes of the interviews were transcribed and analysed using the classic method of content analysis ${ }^{8}$ with an emphasis on the discovery of dominant themes. These themes were identified by a descriptive label, which helped to organise the text within and between transcripts for comparison. ${ }^{6}$ A coding manual was maintained to list codes and their definitions; this was modified as necessary. After this descriptive coding, all transcripts were reviewed using the final coding manual to ensure that all possible codes had been applied, even to the early transcripts. Two coders coded all 12 transcripts to ensure consistency and transparency of the coding. Any discrepancies were resolved by discussion.

\section{RESULTS}

The emergent themes and descriptive codes that emerged from the focused interviews are presented below.

\section{Research understanding and preferences}

Satisfaction with care and research in the institution Overall, there was unanimous praise for the doctors $(n=11$; $92 \%$ ) and the health care institution in which the participants received their care $(n=12 ; 100 \%)$. When asked: "If you knew that research was being done in the institution, how would you feel about it?" all of the participants felt it was "positive" and some thought it would probably enhance their feelings about the institution.

Certainly a primary way that we make advances in medical technology is by research. And, if you're not doing research, that suggests to me that you're justyou're stuck in the status quo; doing experimentation and research tells me you're out trying to further the cause of medicine. That's really what it's all about.

Familiarity with research terms and participating in new stroke trials

The majority ( $n=10 ; 83 \%$ ) of the participants had a moderate to good understanding of terms such as "research", "clinical trials", and "informed consent", and there was unanimous consensus among them that it was important that new treatments for stroke should be developed. The same 10 participants also said they would be receptive to being involved in a trial of a new treatment for stroke. Not only were they hopeful that new trials would be personally beneficial to them in case of another stroke, but, overall, "doing good for others" was given as a reason for participation.

I would be interested in it-not afraid to try new stuff. No problem with me. If it can help develop better techniques in stroke, I'd be interested. That's good to do. It can help make better stuff for people.

However, when asked "about doctors treating patients who have had a stroke with new and untested interventions", these altruistic feelings were somewhat tempered by some ambivalence in half of the sample $(n=6 ; 50 \%)$.

\section{I don't know. I would have to think about that because I want to see how many people it has been tested on before I can use this drug. Most likely, I would say I'll use the drug. I'll be a guinea-pig, but I would have to see how many people first.}

\section{Treatment for stroke without informed consent}

Although almost all of the participants $(n=11 ; 92 \%)$ thought it was "OK" to treat patients who had had a stroke with new and untested interventions if the patient gave informed consent, half ( $n=6 ; 50 \%$ ) were ambivalent about giving treatment for stroke without informed consent. An example of this ambivalence was:

It shouldn't be done unless they did have the informed consent of that patient because untested drugs or 
treatments certainly can have unexpected results, and I think a patient has to understand that there are risks involved in doing that, but if a patient is fully informed of all the risks and then still says yes, I want to participate, then that's fine. I wouldn't expect the doctor to apply those new and untested methods to a patient who hasn't given that informed consent.

However, when asked how he would feel if his doctor treated him with an investigational drug for stroke without his informed consent, this same participant replied:

Ah, I guess if the results were good, I would say thank you. But if, if the results were bad, I would be really upset.

\section{Knowledge and preferences about ERS Initial knowledge of ERS and participation after explanation}

Ten of the 12 participants (83\%) were initially confused about the distinction between "research for stroke" and "emergency research for stroke". However, after the interviewer explained the difference by distinguishing preventive or rehabilitative research from interventional research under normal and emergency situations, 11 (92\%) said they would participate in the latter.

\section{Decisional information for patients}

When asked: "What information would be important for you to know if you had to make the decision to agree or consent to an emergency intervention in a research trial for stroke?" there was unanimous agreement $(n=12 ; 100 \%)$ on knowing the risks and the consequences of such an intervention.

\section{[J]Ust to know that it's going to give me a good shot and} get better. That's basically it.

While 10 of the respondents (83\%) considered "death" as the most important risk to be considered when making the decision to be involved in ERS, most thought that it might be a risk worth taking if the alternatives were worse, as in "being a vegetable".

\section{Consent in ERS}

Importance of surrogate consent in ERS

In the case where people could not consent for themselves, nine of the $12(75 \%)$ participants thought that it would be important for a family member/surrogate to give consent before being entered in the trial. They wanted the family member/surrogate to know about the risks and benefits before giving consent. These same nine participants also had a high level of confidence in the ability of the family member or surrogate to make an accurate decision about involving them in a research project for stroke. In some instances they had discussed "what to do if I had another stroke" with their family.

\section{The physician as surrogate decision maker in ERS}

In the case where a doctor could not obtain consent from the patient or a family member/surrogate in sufficient time, there was almost unanimous ( $n=11 ; 92 \%)$ agreement that the doctor should make the decision and enrol them in the study.

You know, I mean straight out, if nobody can be contacted, it would be better them having to do what they got to do.
Well, I think that they should go ahead and do their research even if I can't speak, or if nobody's around like a family member or guardian.

\section{DISCUSSION}

The findings revealed that studying individuals most likely to be directly affected by ERS could yield important and surprising information about their values and beliefs about serving as ERS participants. The participants thought it was important that new treatments for stroke should be developed and the majority ( $n=10 ; 83 \%$ ) were receptive to being involved in a trial. Their motivation to participate in research extended beyond their hope for personal benefit and reflected altruistic concerns. Despite this willingness to participate, half of them were dubious about the use of investigational interventions without informed consent, which lends support to the widespread emphasis on the importance of informed consent and cautions about the use of the exemption in emergency research. ${ }^{9}$ Although concern has been expressed about the accuracy of surrogate consent, ${ }^{10}$ as well how to select a surrogate, ${ }^{11}$ most participants thought that family members should provide consent for them. During the interviews, many seemed to have specific family members in mind, but we did not investigate this point further in this study. In this pilot study, $75 \%$ of the participants were confident that immediate family members could serve as effective surrogates. Further studies are needed to define which family member patients would regard as the ideal surrogate.

A surprising and potentially important finding was the willingness of patients to regard the treating physician as a surrogate. Eleven (92\%) stated that, if the patient or family were not able to consent, then the treating physician should make the decision. There was, in short, a strong faith in the physician. Although we did not explore whether this faith was predicated on the belief that the physician would offer them "treatment" as opposed to enrolment in a trial, the level of trust was remarkable. Clearly, further research is needed to clarify the meaning of this preference, especially to explore whether a therapeutic misconception was at work. ${ }^{12}$ This finding was consistent across gender and race despite the fact that the literature suggests a strong mistrust of clinical research and research institutions among African Americans. ${ }^{13} 14$ We did not explore whether this trust extended to the health care system generally or to other locations in our community where ERS might occur. Nevertheless, in this small study, there was a strong sense of gratitude for the treatment received as well as a commitment to improving treatments for stroke that reflected very positive attitudes towards physicians and the health care institution where the participants were treated.

\section{LIMITATIONS OF THE PRESENT STUDY AND FUTURE RESEARCH}

This study followed the method outlined for rigorous qualitative research. ${ }^{6}$ The self-report method is strong with respect to its directness and versatility. If we want to know what people think, feel, or believe, the most direct means of gathering the information is to ask them about it. This method of collecting data yielded information that would be difficult, if not impossible, to gather by any other means. Despite the advantages, verbal reports share an important weakness, namely, the question of the validity and accuracy of self-report. ${ }^{68}$ It would have been ideal to reconfirm our findings with the actual participants.

The present study was designed to identify areas for the further investigation of patients who are most likely to be 
included in ERS, based on the belief that these individuals constitute the "relevant community" that should be the focus for community consultation. However, the results of the present study are based on the responses of participants who had already survived a stroke. Therefore, the level of trust expressed towards the physician and the health care institution may be a byproduct of their own stroke outcome and their satisfaction with the care they received. Additionally, the findings from this small sample are not generalisable to all people who have sustained a stroke. Thus future studies should include a larger sample, and the definition of the relevant community broadened to include those individuals who have not suffered a stroke, but who are at risk.

Despite these limitations, this study is the first to provide empirical data on the important ethical issue of waiving informed consent in ERS. Data collected in the present study will be used to formulate questions for further interviews with a broader sample of an enlarged relevant community, and to develop a guide for focus groups that will, hopefully, more reliably identify the values and concerns that are central to this population. Our long term goal is to develop and test a reliable and validated method for identifying the values and preferences of the relevant community(ies) for meeting the emergency research exemption from informed consent requirements. Such a method would be a boon to investigators struggling to meet research requirements, and would also provide empirically sound data on the values and preferences of the community(ies) towards participation in emergency research.

\section{Authors' affiliations}

C E Blixen, Department of Biostatistics and Epidemiology, The Cleveland Clinic Foundation, Cleveland, $\mathrm{OH}$, USA

G J Agich, Department of Bioethics, The Cleveland Clinic Foundation
This research was funded by the Research Programs Committee and the Division of Clinical Research at the Cleveland Clinic Foundation, Cleveland $\mathrm{OH}$, USA. The researchers and their work were independent of the funders throughout the study.

Competing interests: none declared

\section{REFERENCES}

1 Department of Health and Human Services, Food and Drug Administration, Office of the Secretary. Protection of human subjects; informed consent and waiver of informed consent requirement in certain emergency research; final rules. (21 CFR Part 50, 45 CFR Part 46) Washington, DC: Government Printing Office, 1996:51497-533.

2 Baren JM, Anicetti JP, Ledesma S, et al. An approach to community consultation prior to initiating an emergency research study incorporating a waiver of informed consent. Acad Emerg Med 1999;6:1210-5.

3 Food and Drug Administration. Guidance for institutional review boards, clinical investigators, and sponsors: exemption from informed consent for emergency research. Washington, DC: Government Printing Office, 2000:1-21.

4 Kremers MS, Whisnant DR, Lowder LS, et al. Initial experience using the Food and Drug Administration guidelines for emergency research without consent. Ann Emerg Med 1999;33:224-9.

5 Biros MH, Fish SS, Lewis RJ. Implementing the Food and Drug Administration's final rule for waiver of informed consent in certain emergency research circumstances. Acad Emerg Med 1999;6:1272-82.

6 Marshall C, Rossman G. Designing qualitative research, 3rd ed. Thousand Oaks, CA: SAGE, 2003.

7 American Heart Association. Heart disease and stroke statistics - 2005 update. Dallas, TX: American Heart Association, 2005.

8 Strauss A. Qualitative analysis for social scientists. New York, NY: Cambridge University Press, 1988.

9 Brody BA, Katz J, Dula A. In case of emergency: no need for consent. Hastings Cent Rep 1997; 27(1):7-12.

10 Fagerlin A, Ditto PH, Danks JH, et al. Projection in surrogate decisions about life-sustaining medical treatments. Health Psychol 2001;20:166-75.

11 Amdur R, Bachir N, Stanton E. Selecting a surrogate to consent to medical research. IRB: Ethics and Human Research 2000;22(4):7-11.

12 Lidz C, Appelbaum P, Grisso T, et al. Therapeutic misconception and the appreciation of risks in clinical trials. Soc Sci Med 2004;58:1689-97.

13 Corbie-Smith G, Thomas SB, St George DM. Distrust, race, and research. Arch Intern Med 2002;162:2458-63.

14 Shavers VL, Lynch CF, Burmeister LF. Racial differences in factors that influence the willingness to participate in medical research studies. Ann Epidemiol 2002;12:248-56. 